\title{
ANALISIS KEBERLANJUTAN USAHATANI KOPI ARABIKA BAWAKARENG KECAMATAN SINJAI BARAT KABUPATEN SINJAI
}

\author{
(Sustainability Analysis of Bawakareng Arabica Coffee Farm in West \\ Sinjai District, Sinjai District) \\ ${ }^{1}$ Awaluddin, ${ }^{2}$ Nuraeni dan ${ }^{2}$ Mais Ilsan \\ ${ }^{1}$ Pascasarjana Universitas Muslim Indonesia \\ ${ }^{2}$ Jurusan Agribisnis Fakultas Pertanian Universitas Muslim Indonesia
}

\begin{abstract}
Indonesian arabica coffee is now a special coffee and is the best type of coffee, with a distinctive aroma because it has a special market. Its potential development in Indonesia is still very open, especially with the shift of ordinary coffee consumers to specialty coffee. This study aims to analyze the sustainability of Bawakaraeng Arabica coffee farming. This research was conducted in Sinjai Barat Subdistrict, Sinjai Regency, which took place from May to August 2017. Sampling / respondents were conducted randomly as many as 60 farmers. The data obtained were analyzed using the Multidimensional Scaling (MDS) approach which was the development of the Raled SBH method. The results showed that the production and income of Bawakaraeng Arabica coffee farming was less profitable for farmers because income per month for arabica coffee (peco) was approximately Rp. 340,981 and for Arabica coffee (logs) income per month Rp. 439,618, this is far below the minimum wage (UMP) of South Sulawesi province of Rp. 2,435,625 per month. Development of Arabica Bawakaraeng coffee farming based on ecological dimensions, economic dimensions, socio-cultural dimensions, infrastructure and technology dimensions, unsustainable legal and institutional dimensions.
\end{abstract}

Keywords : Arabica coffee, production, income, farming

\section{PENDAHULUAN}

Kopi adalah komoditas perkebunan yang perannya dalam perekonomian nasional sangat penting, enam kontribusi komoditas kopi terhadap ekonomi nasional yaitu: (1) Sebagai sumber devisa negara, (2) Pendapatan petani,

Penciptaan lapangan kerja,

pembanguan wilayah, (5) Pendorong agribisnis dan agroindustri,

Pendukung konservasi lingkungan.

Indonesia adalah penghasil kopi terbesar ketiga di dunia setelah Brasil dan Vietnam namun demikian produktivitas tanaman kopi di Indonesia baru mencapai $771 \mathrm{~kg}$ biji kopi/hektar/tahun untuk kopi robusta dan $787 \mathrm{~kg}$ biji kopi/hektar/tahun untuk kopi arabika. Produktivitas tanaman ini tergolong sangat rendah bila dibanding negara pesaing seperti Vietnam yang produktivitas tanamannya telah mencapai $1.542 \mathrm{~kg} / \mathrm{ha} / \mathrm{tahun}$.

Peluang untuk meningkatkan produktifitas tanaman kopi Indonesia masih sangat terbuka lebar sebab Indonesia memiliki iklim tropis yang secara agronomis sangat cocok untuk pengusahaan kedua jenis kopi tersebut 
(Sudjatmoko. 2013). Produktivitas dengan bergesernya konsumen kopi biasa tanaman juga sangat berpeluang untuk ke kopi specialty di negara-negara ditingkatkan sebab produktivitas tanaman kopi di Indonesia baru mencapai sekitar $50 \%$ dari potensi yang mampu dicapai.

Sampai dengan tahun 2012 luas areal tanaman kopi di Indonesia tercatat 1.233.982 hektar dengan komposisi pengusahaan tanaman kopi nasional masih didominasi oleh perkebunan rakyat seluas 1.185.239 hektar atau (96,4\%) perkebunan besar swasta hanya seluas 26.185 hektar $(2,12 \%)$ dan perkebunan besar negara seluas 22.578 hektar (1,84\%) (Sudjatmoko, 2013).

Dalam hal penciptaan lapangan kerja komoditas kopi memberikan lapangan kerja kepada 1.88 juta KK dengan luas kepemilikan rata-rata 0.6 hektar, sampai dengan saat ini tanaman kopi di Indonesia masih didominasi kopi robusta $(83 \%)$ di banding kopi arabika (17\%) sementara pasar internasional lebih menyukai kopi arabika (Ditjenbun, 2012).

Kopi arabika Indonesia dewasa ini banyak menjadi kopi specialty yang merupakan jenis kopi dengan citarasa terbaik, dengan aroma yang bersifat khas karena itu memiliki pasar yang khusus potensi pengembangannya untuk Indonesia masih sangat terbuka terutama

\section{konsumen seperti Amerika Serikat.}

Beberapa jenis kopi arabika Indonesia tercatat sebagai kopi specialty single origin Indonesia yang mempunyai reputasi dipasar internasional karena mutu dan cita rasanya antara lain adalah : Mandailing dan Lintong Coffee (Sumatra Utara), Gayo Mountain Coffee (Aceh), Java Arabika Coffee (Jawa Timur), Bali Kintamani Coffee (Bali), Toraja dan Kalosi Coffee (Sulawesi-Selatan), Flores Bajawa Coffee (NTT), Baliem Coffee (Papua), Luwak Arabika Coffee.

Wilayah pegunungan propinsi Sulawesi - Selatan sangat cocok ditanami kopi arabika karena suhu dan curah hujannya, kopi arabika sangat popular dengan sebutan "kopi Toraja" yang telah lama disenangi sebagian besar pencinta kopi di dunia karena citarasanya yang khas dan aromanya yang lembut serta seimbang.

Diperkirakan hasil pertanian kopi arabika di Sulawesi Selatan sekitar 7.000 ton yang produksinya tersebar dibeberapa kabupaten yaitu Kabupaten Tana Toraja, Enrekang, Gowa, Sinjai dan Kabupaten Mamasa di Sulawesi Barat. Namun rendahnya daya saing produk kopi baik 
kopi biji maupun kopi olahan karena tidak terlepas dari masalah-masalah seperti kurangnya pengetahuan penanganan panen dan pasca panen oleh petani sehingga mutu biji kopi masih rendah baik sebagai bahan baku pada industri pengelolaan kopi maupun untuk ekspor.

Jaminan pasokan bahan baku kopi masih rendah baik dalam hal jumlah, mutu maupun kontinutas, produktivitas tanaman kopi masih sangat rendah sedangkan kesadaran petani untuk menggunakan benih unggul juga masih rendah. Sebagian besar areal kopi dikelola dalam bentuk perkebunan rakyat dengan penerapan kultur teknis yang belum sesuai dengan teknologi anjuran, terbatasnya fasilitas produksi dan pengolahan biji kopi misalnya mesin peralatan pengering, pengupas dan sortasi utamanya ditingkat skala kecil dan menengah, terbatasnya penguasaan teknologi proses pada tahap roasting, kurangnya kemampuan melakukan inovasi dan diversifikasi produk sesuai dengan permintaan pasar domestik maupun internasional (Fikriyah, 2012).

Kabupaten Sinjai adalah salah satu kabupaten penghasil kopi arabika yang berada di kawasan pegunungan
Bawakaraeng dengan luas areal tanaman kopi sekitar 2.950 ha yang dikelolah sebanyak 2.187 petani. Sejak tahun 2013 Kabupaten Sinjai termasuk salah satu kabupaten yang bermitra dengan Yayasan Pensa Global Agromandiri (YAPENSA) dalam program "The Bawakaraeng Sustainable Coffee Value Chain".

Kopi Arabika di kawasan Gunung Bawakaraeng seluruhnya diproduksi oleh petani kecil dengan luas lahan rata-rata 0,5-1 ha. Pada umumnya petani menanam kopinya bercampur dengan tanaman keras lainnya dan tanaman semusim dalam bentuk agroforestry. Jenis kopi yang dikembangkan di daerah kawasan Gunung Bawakaraeng adalah Arabika varietas Lini S795 dan HDT (hybrid de timor), dalam jumlah kecil ada juga varietas keturunan Catimor.

\section{METODE PENELITIAN}

\section{Lokasi dan Waktu Penelitian}

Penelitian ini dilakukan di Kecamatan Sinjai Barat Kabupaten Sinjai, karena Kabupaten Sinjai merupakan salah satu kabupaten yang bermitra dengan YAPENSA pada program pengembangan kopi Bawakaraeng (Arabika). Waktu penelitian akan dilaksanakan selama tiga 
Bulan mulai dari Bulan Mei sampai Bulan Agustus 2017.

\section{Jenis dan Sumber Data}

Jenis dan sumber data yang digunakan dalam penelitian ini adalah:

1. Data primer, yaitu data yang diperoleh langsung dari responden petani mitra dan pakar melalui wawancara dan observasi dengan menggunakan kuisioner (daftar pertanyaan).

2. Data sekunder, yaitu data yang diperoleh dari sumber yang ada kaitannya dalam usaha pengembangan komoditi kopi, terutama dari lembaga pemerintahan, lembaga penelitian, serta instansi terkait.

\section{Teknik Pengumpulan Data}

Pengumpulan data dilakukan dalam penelitian ini adalah dengan cara :

1. Observasi, yaitu pengumpulan melalui pengamatan langsung terhadap kegiatan responden, dengan maksud untuk memperoleh data primer.

2. Wawancara, yaitu pengumpulan data melalui tanya jawab dengan responden yang menggunakan daftar pertanyaan atau kuesioner untuk memperoleh data primer dan data sekunder.

3. Dokumentasi, yaitu pengumpulan data melalui jurnal-jurnal, hasil hasil penelitian terdahulu, dan buku-buku, literatur yang ada kaitannya dengan penelitian guna memperoleh data sekunder.

\section{Populasi dan Sampel}

Populasi petani kopi sebanyak 12 kelompok tani, yang terdiri dari 20 orang anggota setiap kelompok tani. Total populasi petani mitra kopi Arabika Bawakaraeng di Kecamatan Sinjai Barat Kabupaten Sinjai sebanyak 240 petani. Pengambilan sampel/responden dilakukan secara acak yaitu responden perwakilan dari setiap kelompok dengan jumlah disesuaikan dengan kondisi kelompok, sehingga jumlah responden sebanyak 60 petani. Responden pakar diambil secara purposive yaitu pakar yang memahami sistem perkopian.

\section{Metode Analisis Data}

Analisis keberlanjutan usaha tani kopi Arabika Bawakaraeng dilakukan analisis dengan pendekatan Multidimensional Scaling (MDS) yang 
merupakan pengembangan dari metode Raled SBH yang digunakan untuk menilai status keberlanjutan usaha tani kopi Arabika Bawakaraeng di Kecamatan Sinjai Barat Kabupaten Sinjai serta analisis pendapatan usahataninya.

Analisis Pendapatan Usahatani dengan

Rumus :

$\pi=\mathrm{TR}-\mathrm{TC}$

Dimana :

$\pi=$ Pendapatan Bersih

$\mathrm{TR}=$ Total Revenue (Pendapatan Kotor)

$\mathrm{TC}=$ Total Cost (Total Biaya Usahatani)

TC (Total Cost (Total Biaya Usahatani) dirumuskan sebagai berikut:

$$
\mathrm{TC}=\mathrm{TVC}+\mathrm{TFC}
$$

Dimana :

Tabel 1. Kategori Status Keberlanjutan Pengelolaan Usaha tani Kopi Arabika Bawakaraeng Berdasarkan Nilai Indeks Hasil Analisis Raled SBH
TR (Total Revenue) dirumuskan sebagai berikut:

$$
\mathrm{TR}=\mathrm{Q} \times \mathrm{Py}
$$

Dimana :

Q = Kuantitas Produksi

$\mathrm{Py}=$ Harga

Penentuan variabel pengelolaan tanaman kopi secara berkelanjutan yang mencakup lima dimensi yaitu : (1). Dimensi Ekologi, (2). Dimensi Ekonomi, (3).Dimensi Sosialbudaya, (4).Dimensi Teknologi dan Infrastruktur, (5).Dimensi Hukum dan Kelembagaan.

\begin{tabular}{cc}
\hline \hline Nilai Indeks & Kategori \\
\hline \hline $0-25$ & Buruk (Tidak Berkelanjutan) \\
$26-50$ & Kurang (Kurang Berkelanjutan) \\
$51-74$ & Cukup (Cukup Berkelanjutan) \\
$75-100$ & Baik (Sangat Berkelanjutan) \\
\hline \hline
\end{tabular}

Sumber : Sugeng Budi Harsono (2014)

Analisis Multi Dimensional keberlanjutan usaha tani kopi Arabika Scaling (MDS) selain menentukan nilai Bawakaraeng di Kecamatan Sinjai Barat indeks keberlanjutan juga menyediakan Kabupaten Sinjai. analisis leverage yaitu untuk mengetahui Setiap atribut pada masing masing atribut yang sensitif terhadap dimensi diberikan skor berdasarkan keberlanjutan usahatani kopi Arabika scientific judgment responden. Rentang Bawakaraeng dan nilai Monte Carlo skor berkisar antara 0-2 mulai dari yang sebagai pembanding nilai indeks buruk 0 (nol) sampai baik 2 (dua). 
Tabel 2. Atribut-Atribut dan Skor Keberlanjutan Usahatani Kopi Arabika Bawakaraeng.

\begin{tabular}{lllll}
\hline \hline Dimensi dan Variabel & Skor & Baik & Buruk & Keterangan \\
\hline \hline Dimensi Ekologi & & & & \\
Dimensi Ekonomi & & & & \\
Dimensi Sosial Budaya & & & & \\
Dimensi Teknologi dan Infrastruktur & & & & \\
Dimensi Hukum dan Kelembagaan & & & \\
\hline \hline
\end{tabular}

Berdasarkan metode Multi yang di kaji mempunyai nilai indeks dimensional Scaling (MDS) posisi titik berkelanjutan lebih besar atau sama berkelanjutan dapat divisualisasikan dengan $50 \%$, maka sistem dikatakan melalui sumbu horisontal dan sumbu berkelanjutan (sustainable) dan tidak vertikal. Dengan proses rotasi posisi titik berkelanjutan jika nilai indeks kurang dapat divisualisasikan dengan nilai dari $50 \%$. Ilustrasi hasil ordinasi nilai indeks berkelanjutan diberi nilai skor $0 \%$ indeks berkelanjutan dapat dilihat pada (buruk) dan $100 \%$ (baik). Jika sistem gambar berikut:

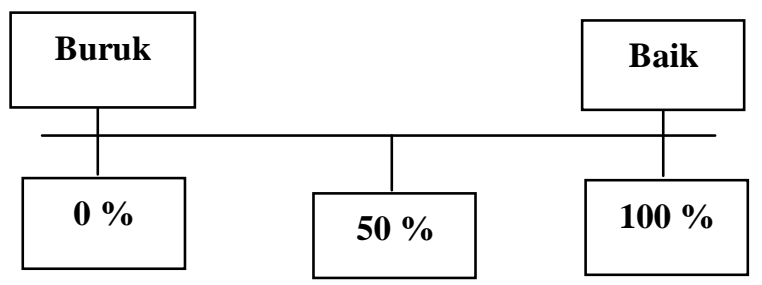

Gambar 1. Ilustrasi Indeks Keberlanjutan Usahatani kopi Arabika Bawakaraeng Sebesar $50 \%$ (Berkelanjutan)

\section{HASIL DAN PEMBAHASAN}

Kecamatan Sinjai Barat merupakan salah satu kecamatan yang memiliki areal tanaman kopi arabika seluas 835 ha dengan produksi 588 ton. Secara administratif Kecamatan Sinaji Barat sebelah selatan berbatasan dengan Kecamatan Kabupaten Bone sebelah timur berbatasan dengan Kecamatan Sinjai Tengah sebelah utara berbatasan dengan Kabupaten Bulukumba sebelah Barat berbatasan dengan Kabupaten Gowa.

Kecamatan Sinjai Barat secara astronomis terletak antara S 05.731 dan E 120.1039, dengan ketinggian 1100 meter diatas permukaan laut. Luas Kecamatan Sinjai Barat 135,53 km² dengan jumlah penduduk 23,927 orang yang terdiri atas laki-laki 11,877 dan wanita 12,050, 
Kecamatan Sinjai Barat terdiri dari 7 Kabupaten Sinjai dapat dilihat pada Tabel

Desa dan 2 Kelurahan. 3.

Analisis pendapatan usahatani kopi Arabika Bawakaraeng

\section{Analisis Biaya}

Data analisis pendapatan usahatani

kopi Arabika Bawakaraeng (Peco dan

Gelondongan) di Kecamatan Sinjai Barat

Berdasarkan Tabel 3 bahwa analisis usahatani kopi Arabika Bawakaraeng (Peco) menunjukkan bahwa jumlah pengeluaran biaya variable dan biaya tetap sebanyak Rp. 2,593,102 pertahun dengan luasan 11,2 ha.

Tabel 3. Analisis Biaya Rata-Rata Usahatani kopi Arabika Bawakaraeng (Gelondongan)

\begin{tabular}{lrr}
\hline \hline \multicolumn{1}{c}{ Jenis Biaya } & $\begin{array}{c}\text { Jumlah } \\
(\mathbf{K g})\end{array}$ & Nilai \\
\hline \hline 1. Pupuk Urea & 60 & 131,290 \\
2. Pupuk NPK & 105 & 261,719 \\
3. Pupuk Kompos & 900 & 655,000 \\
4. Fungisida & 0 & 33,250 \\
5. Herbisida & 1 & 83,243 \\
6. Insectisida & 0 & 6,000 \\
7. Tenaga Kerja Pemupukan & 2 & 147,742 \\
8. Tenaga Kerja Pemangkasan & 2 & 98,167 \\
9. Tenaga Kerja Panen & 6 & 357,051 \\
10. Sewa Alat Pengolahan & 0 & 0 \\
\hline \hline & & \\
\hline \hline Pajak Biaya Tetap & $\mathbf{1}$ & 36,744 \\
\hline \hline
\end{tabular}

\begin{tabular}{|c|c|c|}
\hline & Berdasarkan & Tabel \\
\hline nalisis & usahatani & kopi \\
\hline
\end{tabular}

Analisis Produksi dan Penerimaan

menunjukkan bahwa jumlah pengeluaran biaya variable dan biaya tetap sebanyak Rp. 1,810,206, dengan luasan 19,9 ha.

Data analisis produksi dan pendapatan usahatani kopi Arabika Bawakaraeng (Peco dan Gelondongan) dapat dilihat pada Tabel 4 dan Tabel 5. 

Kabupaten Sinjai

Tabel 4. Rata-Rata produksi Usahatani Kopi Arabika Bawakaraeng (Peco)

\begin{tabular}{ccc}
\hline \hline Produksi Kopi & $\begin{array}{c}\text { Jumlah } \\
\text { Panen }\end{array}$ & Nilai \\
\hline \hline 1 & 150 & $1,901,952$ \\
2 & 254 & $3,346,976$ \\
3 & 107 & $1,435,952$ \\
\hline \hline TOTAL & $\mathbf{5 1 1}$ & $\mathbf{6 , 6 8 4 , 8 8 0}$ \\
\hline \hline
\end{tabular}

yang menjual kopinya dalam bentuk gelondongan lebih menguntungkan dibandingkan dengan petani yang menjual kopinya dalam bentuk gelondongan karena perbedaan selisih harga jual.

\section{Berdasarkan Tabel}

menunjukkan bahwa Usahatani kopi Arabika Bawakaraeng

(Peco) menunjukkan bahwa rata-rata produksi selama satu tahun sebanyak 511 liter dengan nilai jual sebesar Rp. 6,684,880 dengan luasan sebesar 19,9 Ha.

Tabel 5. Rata-Rata Produksi Usahatani kopi Arabika Bawakaraeng (Gelondongan)

\begin{tabular}{ccc}
\hline \hline Produksi Kopi & \multirow{2}{\text{Jumlah}}{} & Nilai \\
(Liter) & \\
\hline \hline 1 & 428 & $1,681,192$ \\
2 & 532 & $2,140,138$ \\
3 & 725 & $3,264,300$ \\
\hline \hline TOTAL & $\mathbf{1 , 6 5 8}$ & $\mathbf{7 , 0 8 5 , 6 3 0}$ \\
\hline \hline
\end{tabular}

Berdasarkan Tabel 5 produksi kopi Arabika Bawakaraeng (Gelondongan) menunjukkan bahwa jumlah rata-rata produksi pada panen pertama sampai panen ketiga sebanyak 1,658 liter dengan nilai penjualan sebesar Rp. 7,085,630.Pada umumnya petani

\section{Analisis Rata-Rata Pendapatan Usahatani kopi Arabika Bawakaraeng}

$$
\text { Pendapatan rata-rata petani }
$$

responden didapat dari total rata-rata penerimaan dikurangi total biaya, Hasil analisis usahatani kopi Arabika Bawakaraeng (Peco dan gelondongan), dapat dilihat pada Tabel 6 dan Tabel 7.

\begin{tabular}{rlr} 
Tabel & 6. & $\begin{array}{l}\text { Analisis } \\
\text { Usahatani } \\
\text { Bawakaraeng }\end{array}$ \\
& $\begin{array}{r}\text { Rata-Rata } \\
\text { Kopi }\end{array}$ & $\begin{array}{r}\text { Pendapatan } \\
\text { Arabika }\end{array}$ \\
\hline \hline & Uraian & Nilai (Rp) \\
\hline \hline 1. & Penerimaan & 6.684 .881 \\
2. & Total Biaya & 2.593 .102 \\
3. & Pendapatan & 4.091 .779 \\
\hline \hline
\end{tabular}

Berdasarkan Tabel 6, hasil analisis rata-rata pendapatan usahatani kopi Arabika Bawakaraeng (Peco) kurang menguntungkan bagi petani karena jumlah pendapatan bersih dalam satu tahun sebanyak Rp.4.091.779, sedangkan pendapatan perbulan sebanyak Rp. 340.981. 
Tabel 7. Analisis Pendapatan Usahatani Kopi Arabika Bawakaraeng (Gelondongan)

\begin{tabular}{llr}
\hline \hline & Uraian & Nilai (Rp) \\
\hline \hline 1. & Penerimaan & 7.085 .630 \\
2. & Total Biaya & 1.810 .206 \\
3. & Pendapatan & 5.275 .424 \\
\hline \hline
\end{tabular}

Berdasarkan hasil analisis tersebut diatas maka usahatani kopi Arabika Bawakaraeng (Peco dan Gelondongan) menguntungkan bagi petani karena jumlah pendapatan rata-rata dalam satu bulan sebanyak Rp. 340.981 (Peco) dan Rp.439.618 (Gelondongan).

\section{Analisis keberlanjutan kopi Arabika Bawakaraeng}

Hasil analisis keberlanjutan usahatani kopi Arabika Bawakaraeng di Kecamatan Sinjai Barat Kabupaten Sinjai dimana atribut - atribut yang digunakan dalam menilai pengelolaan keberlanjutan usahatani kopi Arabika Bawakareng teridiri atas 5 (lima) dimensi yaitu : (1). Dimensi ekologi 48,75 persen dengan status kurang berkelanjutan, (2). Dimensi ekonomi 37,44 persen dengan status kurang berkelanjutan, (3). Dimensi sosial budaya 48,32 persen dengan status kurang berkelanjutan, (4). Dimensi infrastruktur dan teknologi 40,47 persen dengan status kurang berkelanjutan, (5). Dimensi hukum dan kelembagaan 32,09 persen dengan status kurang berkelanjutan.

Berdasarkan hasil analisis Monte Carlo pada tingkat kepercayaan 95 persen untuk masing-masing dimensi dengan analisis Multi Dimensional Scaling (MDS) dapat dilihat pada Tabel 8.

Tabel 8. Hasil Analisis Masing-Masing Dimensi Dan Monte Carlo Pada Tingkat Kepercayaan 95 persen

\begin{tabular}{lcc}
\hline \hline \multicolumn{1}{c}{ Dimensi Keberlanjutan } & Hasil MDS & Hasil Monte Carlo \\
\hline \hline Dimensi Ekologi & 48,75 & 48,28 \\
Dimensi Ekonomi & 37,44 & 37,21 \\
Dimensi Sosial dan Budaya & 48,32 & 47,28 \\
Dimnesi Infrasruktur dan Teknologi & 40.47 & 39,05 \\
Dimensi Hukum dan Kelembagaan & 32,09 & 31,95 \\
\hline \hline
\end{tabular}

Hasil analisis Monte Carlo pada tingkat kepercayaan 95 persen untuk masing - masing dimensi dengan analisis Multi Dimensional Scalling (MDS) menunjukkan selisih yang relatif kecil dapat dilihat pada Tabel 8, ini menunjukkan bahwa sistem yang dikaji memiliki tingkat kepercayaan yang tinggi. Hasil analisis 34 (tiga puluh empat) atribut dari 5 (lima) dimensi yaitu: 
(1). Dimensi ekologi, (2). Dimenesi hukum dan kelembagaan, terdapat 14 ekonomi, (3). Dimensi Sosial budaya, (4). atribut yang sensitif dapat dilihat pada Dimensi Infrastruktur, (5). Dimensi Tabel 9.

Tabel 9. Atribut Indeks Keberlanjutan Usahatani Kopi Arabika Bawakaraeng

\begin{tabular}{clc}
\hline \hline Dimensi & \multicolumn{1}{c}{ Atribut } & Skor \\
\hline \hline \multirow{2}{*}{ Ekologi } & 1. Luas lahan usahatani kopi & 2,54 \\
& 2. Informasi pasar dan harga kopi & 3,84 \\
& 3. Tempat memasarkan kopi & 2,58 \\
& 4. Jenis Produk Kopi yang di jual Petani & 3,82 \\
Sosial Budaya & 5. Status lahan usahatani kopi & 4,68 \\
& 6. Standarisasi mutu kopi & 2,99 \\
& 7. Tindakan pemupukan & 1,62 \\
Infra Struktur & 8. Tindakan pemangkasan tanaman kopi & 1,96 \\
& 9. Tingkat penguasaan dan penerapan teknologi & 1,79 \\
& 10. Kondisi prasarana jalan desa & 2,26 \\
& 11. Keberadaan lembaga pengawas mutu & 10,16 \\
Hukum dan & 12. Keberadaan kelompok tani & 16,88 \\
Kelembagaan & 13. Ketersediaan lembaga keuangan & 14,79 \\
& 14. Ketersediaan lembaga sosial & 11,71 \\
\hline \hline
\end{tabular}

Berdasarkan Tabel 9, bahwa jumlah atribut yang sensitif setiap dimensi bervariasi. Dimensi ekologi 1 (satu) atribut, dimensi ekonomi 3 (tiga), dimensi sosial budaya 1 (satu), dimensi infrastruktur 5 (lima), dimensi hukum dan kelembagaan 4 (empat) atribut. Atribut sensitif tersebut berperan sebagai faktor pengungkit (leverage factor) terhadap masing-masing dimensi. Oleh karena itu data ini menjadi dasar informasi tentang atribut yang perlu ditingkatkan dan dijaga kualitasnya. Diharapkan adanya perlakuan tersebut terhadap atribut-atribut sensitive maka indeks keberlanjutan pengelolaan usatani kopi Arabika Bawakaraeng di Kecamatan Sinjai Barat Kabupaten Sinjai.

\section{KESIMPULAN}

Sesuai hipotesis penelitian, maka disimpulkan sebagai berikut :

1. Produksi dan pendapatan usahatani kopi Arabika Bawakaraeng kurang menguntungkan bagi petani karena pendapatan perbulan untuk kopi 
arabika (peco) kurang lebih Rp. 340.981 dan untuk kopi arabika (gelondongan) pendapatan perbulan Rp. 439.618, ini jauh dibawah upah minimum (UMP) Provinsi Sulawesi Selatan sebesar Rp. 2,435,625 perbulan.

2. Pengembangan usahatani kopi Arabika Bawakaraeng berdasarkan dimensi ekologi, dimensi ekonomi, dimensi sosial budaya, dimensi infrastruktur dan teknologi, dimensi hukum dan kelembagaan tidak berkelanjutan.

3. Terdapat satu atribut yang sensitif pada dimensi ekologi, tiga atribut yang sensitif pada dimensi ekonomi, satu atribut yang sensitif pada dimensi sosial budaya, lima atribut yang sensitif pada dimensi infrastruktur dan teknologi, lima atribut yang sensitif pada dimensi hukum dan kelembagaan.

\section{DAFTAR PUSTAKA}

Ade Supriatna. 2010. Pola Kemitraan dalam Peningkatan Efisiensi Pemasaran Kopi Rakyat.Balai Besar Pengkajian dan Teknologi Pertanian, Bogor Jawa Barat.

Ditjen Perkebunan, 2012. Sasaran Luas Areal Komoditas Unggulan Nasional.http://www.ditjenperkebu nan.co.id.
D. Faila Sophia Hartatri, Bernard de Rosari, 2010. Analisis Usahatani dan Rantai Pemasaran Kopi arabika di Kabupaten Manggarai Timur.

Fikriyah, 2012.Dinamika Kopi Sulawesi di Pasar Global dan Pengaruhnya terhadap rantai kopi lokal di Sulawesi-Selatan.Fakultas Matematika dan Ilmu Pengetahuan Alam Program Sarjana Geografi. Universitas Indonesia. Depok.

Ima Aisyah Sallatu, 2016. Analisis Pangsa Pasardan Tataniaga Kopi Arabika di Kabupaten Tanah Toraja dan Enrekang Sulawesi Selatan. Institut Pertanian Bogor.

Jimmi Andar Siahaan, 2008. Analisis Dayasaing Kopi Arabika Indonesia di pasar Internasional. Universitas Jember.

Jef Radianto Saragih. 2010. Kinerja Produksi Kopi Arabika dalam Pendapatan Wilayah Kabupaten Simalungun. Sumut.

Mubyarto, 1989.Pengantar Ekonomi pertanian. LP3ES, Jakarta.

Najiyati, Sri dan Danarti, 2004. Kopi, budidaya dan Penanganan Pasca Panen.Penebar Swadaya Jakarta.

Rahmadityah, 2017. Dampak Program Pemberdayaan Masyarakat Terhadap Produktifitas, Akses Pasar dan Pendapatan Petani Kopi di Bantaeng Sulawesi Selatan.

Soekartwi, 1987. Prinsip Dasar Ekonomi Pertanian dan aplikasinya, Rajawali Press. Jakarta.

Sudjatmoko, 2013.Kopi Sejarah, Botani, Proses Produksi, Pengolahan Produksi Hilir dan Sistem Kemitraan.ICCRI.

Sri Ningsih, dan Danarti, 2004. Kopi, Budidaya dan Penanganan Pasca Panen. Penebar Swadaya. Jakarta. 
Tony, M dan Jeff, N. 2007. Securing the Yayasan Pensa Global Agromandiri, Profitability of the Flores Coffee Industry. ACIAR. Sydney. 